\title{
A Reflection on How We Value our Research (Impacts)...
}

\section{Carlos J.L. Balsas*}

Department of Arts \& Sciences, University at Albany, Albany, USA

\begin{abstract}
This letter to the editor of Planning Magazine was written in response to an article published in the June 2016 issue of the magazine entitled "Research You Can Use-The five most-cited planning researchers". To this day the letter has remained unaddressed by the editor. Therefore, I have taken the liberty to submit it to the Journal of Health \& Medical Informatics, since some of the so called "most-cited" authors have also published on health-related topics, and the points I make in my letter below are valid across multiple disciplinary fields.
\end{abstract}

Keywords: Research; Research impact; Urban planning; Planning magazine; Citation metrics

\section{Letter to the Editor}

Urban and Regional Planning is by its very own nature a multidisciplinary professional field. What distinguishes it from cognate disciplines in the social sciences is its applied service emphasis to specific situations in a multitude of community types. Research is critical to the development of the profession, but often times, the most customary research metrics one finds readily available neglect to capture the impact of time-consuming invaluable service activities and community embeddedness nuances of what many researchers holding academic appointments at universities in north-America are asked to do regularly.

In my particular case, I have taught a considerable number of studio courses, where teams of students and instructors work collaboratively with community leaders, residents, business owners, professional planners and elected officials. Those courses have been centered on identifying problems, studying situations from multiple perspectives and proposing suitable recommendations. I have applied this methodology in a relatively high number of planning studios in both Massachusetts and Arizona, as well as in many planning assignments in California and New York, and in countries ranging from Portugal and the United Kingdom to Brazil and Japan. Many of the public scholarship projects I have coordinated over the years have won state planning awards, however most of them were not captured by any research impact metrics.

Being an assistant professor with at least 10 years of classroom experience on both coasts of the United States, all of which involved different levels of direct engagement with clients, neighborhood organizations, planning departments at various governmental levels, consulting firms, residents, business owners and non-profit leaders has helped me gain invaluable knowledge and experience of multiple planning facets and processes. Team work has been central to planning and I have performed various roles in planning assignments ranging from project manager to specialist. In those roles I was responsible for obtaining funding, writing, analyzing, computing, illustrating and presenting planning analysis, findings and recommendations, sharing them with others, seeking feedback, correcting and refining less clear passages and minor overlooked details, and finally signing off on final products. I also have experience participating in critical meetings, short visits, and complying with tight deadlines.

I only hope that the various constituencies I have served over the years have appreciated the benefits derived from the intersection of planning education, practice and research outcomes, which I attempted to transmit in a myriad of ways, from published books, edited volumes, journals, newsletter and magazine articles, to encyclopedia and dictionary essays and entries. In most situations, if not all, I have attempted to draw implications for planning practice and pedagogy, and to advance the research capacities of the profession; nonetheless, many of those articles, essays and published documents are minimally, if at all, indexed by traditional research databases.

In addition to planning studios, I have also led reviews of general plans for many municipalities in Arizona and the southwest. Those reviews enabled teams of students and teaching assistants to understand not only the substance and principles of urban and regional planning, but also provided an opportunity to contrast how well those regulations have guided development where it matters most: on the ground and on the water and air interfaces. This practice was complemented with the study of a very comprehensive array of planning subjects at both undergraduate and graduate levels.

The presentation of those findings to various community groups have helped to build endogenous capacity and propelled non-profit organizations to write grant proposals and use seed funding from a myriad of organizations to advance their developmental and conservation agendas in real communities; and once again those positive outcomes of research and service efforts are little if at all captured and taken into consideration by research impact databases and university tenure and promotion guidelines. Therefore, relying only on counting citations as the main form of assessing the impacts of research is quite short-side and leaves out a considerable part of what many of us work on in our jobs as instructors and scholars in universities and think-tanks in north-America.

\section{Dear Editor Mrs. Stromberg}

Thank you for informing Planning's readership of the top 5 scholars with the highest number of citations. Your monthly column was one I looked forward to reading in prior issues of the magazine, not because of its title "research you can use" but because of the topics, insights,

*Corresponding author: Carlos J.L. Balsas, Department of Arts \& Sciences, University at Albany, 1400 Washington Ave, Albany, NY 12222, USA, Tel: 518-4424469; E-mail: cbalsas@albany.edu

Received January 19, 2018; Accepted February 01, 2018; Published February 08, 2018

Citation: Balsas CJL (2018) A Reflection on How We Value our Research (Impacts)... J Health Med Informat 9: 300. doi: 10.4172/2157-7420.1000300

Copyright: @ 2018 Balsas CJL. This is an open-access article distributed under the terms of the Creative Commons Attribution License, which permits unrestricted use, distribution, and reproduction in any medium, provided the original author and source are credited. 
synthesis and pertinence of many of the unresolved issues that make professional planning and scholarly thought simultaneously interesting and so difficult. In our current day and age, we are not short of rankings, listings, orderings, hierarchies or metrics. We are however hard pressed for a critical discussion on the value of those metrics and on how they are put to use by outdated governance procedural routines (i.e. blind co-authoring, effort per researcher evidence, contributions to public scholarship, direct impacts on the lives of the most disenfranchised persons among us, etc.) in a myriad of legitimate and spurious set of entities, including mass media and the five largest and monopolizing academic journal publishing houses (i.e. Elsevier, Springer, WileyBlackwell, Taylor \& Francis and Sage), and their relationships between tax-exemptions, corporate profits and genuine progress indicators.

If you are running short of ideas to feature in your column, these sources are quite illuminating:

- Scholarship in Public: Knowledge Creation and Tenure Policy in the Engaged University (2008) by Imagining America: Artists and Scholars in Public Life.

$<$ http://imaginingamerica.org/wp-content/uploads/2015/07/

ScholarshipinPublicKnowledge.pdf $>$
- Special Topic Forum: Critical Scholars in the Machinery of Publishing: Experiences, Reflections, Alternatives. (September 2012) Scandinavian Journal of Management.

$<$ https://www.sciencedirect.com/science/journal/09565221/28/3>

- Alternative Cultures in Planning Research-From Extending Scientific Frontiers to Exploring Enduring Questions (2012) by A. Forsyth.

<http://journals.sagepub.com/doi/10.1177/0739456X12442217>

- Academic Repression, Reflections from the Academic Industrial Complex (2010) by Anthony Nocella et al.

$<$ https://www.akpress.org/academic-repression-reflections-fromthe-academic-industrial-complex.html >

$$
\text { Thank you. }
$$

Carlos Balsas, Ph.D., AICP

Assistant professor

Geography and Planning

University at Albany, SUNY 